\title{
Reform Now, Before It's Too Late!
}

\section{William Mueller}

It is to be hoped that the near future will bring reforms in the mathematical teaching in this country. We are in sad need of them. From nearly all of our colleges and universities comes the loud complaint of inefficient preparation on the part of students applying for admission; from the high schools comes the same doleful cry. ... and educators who have studied the work of (foreign) schools declare that our results in elementary instruction are far inferior.

This is the sobering assessment of the state of American mathematics instruction offered by the Department of Education, reporting on a national study of contemporary educational practices. The indictment runs from the top to the bottom: Universities, colleges, high schools, and elementary schools all get failing grades. Summarizing the situation, the president of Cornell University has remarked simply that: "... our inferiority seems to me to be very marked."

The report's conclusions are hardly a revelation, however, to the many mathematicians and educators whose impassioned critiques of popular mathematical textbooks and instructional methods, especially those used in calculus, have appeared in publications such as this one. Given the uproar, and the grim prognoses for the future, it would seem that every conscientious teacher of mathematics in this country should be duty-bound to reevaluate the misguided attitudes and ineffective educational methods that have taken hold in the classroom.

At least, it seemed that way in 1890. That is the date on the report from the Department of Education (when it was called the Bureau of Education) [3]. The president of Cornell University was C. K. Adams, who delivered his remark to the annual meeting of the New England Association of Colleges and Preparatory Schools, in 1888 [17, p. 24]. The publications "such as this one" included, indeed, the MONTHLY, beginning with its first volume in 1894, and the Bulletin of the American Mathematical Society, which began publication that same year. Both journals, from the very beginning, printed articles, editorials, and reports that expressed a tremendous concern about the way in which American students were learning mathematics. Reading through these today, one might suppose that at the turn of the last century the minds of America's youth were imperiled, American productivity was being threatened, and, indeed, the future of American mathematics was at stake.

This article offers a small sampling of voices from that era. Through a collage of quotations and citations, I've attempted to stir up a little of the dust that was being kicked around 100 years ago. The dust has never really settled. Indeed, I suspect that these voices will elicit an acute sense of retrospective déjà vu among modern readers. This being the case, I propose a simple question: To what extent can the current state of mathematics education be in such a state of "crisis," if the terms of the debate have changed so little in 100 years?

REFORMERS UNITE. By 1900, the American Mathematical Society felt that it was desirable to provide a forum for the "discussions" of education, especially as they related to the undergraduate curriculum. A special session was organized for the Seventh Summer Meeting in New York City, and excerpts from the presentations that were made have been preserved in the Bulletin [12]. Collectively, these excerpts suggest something of the tenor of the "discussions" that were taking place across the country. 
Read a century later, there is a familiar sound to the prescriptions being offered for what was ailing American mathematics education.

Here, for example, is Prof. James Harkness, who presented two papers at the session with titles that would blend in very nicely at any modern-day session on reform: "Courses in differential calculus and differential equations" and "The importance of some preliminary training in applied mathematics":

I urge the necessity of a thorough revision of college courses in differential calculus. The subject is too often taught along traditional lines; the lecturer should ask himself whether certain parts of his subject possess the same importance today that they had in Euler's time. Much might be rejected as of secondary importance in comparison with the newer developments. Our textbooks abound, too, with proofs that are no proofs and with extremely misleading statements. It is very desirable that such proofs should be rejected, or given only with clear indications of their limitations. A graduate student in the theory of functions often finds it impossible to rid his mind of erroneous notions derived from the days when he first began the study of the differential calculus.

It is tempting to characterize Prof. Harkness' presentation in the parlance of our own times. He is "pro-reform," in the sense of rejecting outdated traditional methods in favor of "newer developments." He is, however, simultaneously opposed to "proofs that are no proofs," which a modern-day reformer might regard as a criticism of the simplified, suggestive arguments that guide students through so many of today's "reform" texts. It becomes apparent that one must be extremely careful when applying familiar categories to the past, since they may fail to capture many of the essential issues being raised. I suggest, in this look backward over a century, that simple categories are equally insufficient in the present.

Witness the manner in which Prof. Harkness continues, mixing together what would be considered opposing sides of the modern debate:

While due emphasis should be laid on the fundamental concepts of function, limit, continuity, etc., the work of the undergraduate should be lightened as far as possible. He should not be asked to differentiate $x^{x^{x}}$ or to work out examples which illustrate no general theory and are unlikely to be of use to him later on. Moreover care should be exercised when he comes to applications; the simple cases are usually discussed correctly, but the writers of our textbooks are too apt to go further and attempt a partial and inaccurate discussion of more difficult cases. Here again it would be easy to multiply examples; it will be sufficient to refer to the criteria for maximum and minimum values and to the accounts usually given of the higher singular points on an algebraic curve.

Present-day reformers might cheer on the call for a de-emphasis of mindless symbolic manipulation; at the same time, they might object to the implied criticism of overly simplistic "application-oriented" curricula. Today, Prof. Harkness would be a man without a camp.

It is equally difficult to apply modern categories to Prof. W. F. Osgood, who presented the papers "Shall we try to place the calculus as early as possible?," "How early in the course may the lecture method be used with profit?," and the provocative "Are the best results in graduate work secured from students who have devoted most of their undergraduate time to mathematics or from those who have combined a fair amount of mathematics with a more general culture?" He says:

The fundamental principles of the calculus must be taught in a manner wholly different from that set forth in the textbooks if they are to become flesh and blood to the student. It is an easy method for the teacher to expound the notion of the limit in the opening lectures of the course 
and from there on to appeal to this conception, this mode of thinking, as if it had become a part of the mental machinery of the beginner. No great mistake can be made. The student will indeed learn to perform differentiations and integrations; but he will not make progress in mastering the central ideas of the calculus. The notion must be set forth repeatedly throughout the whole course. A valuable aid in making this notion clear is furnished by the application of the calculus not merely to differential geometry, but (the integral as the limit of a sum having been introduced early in the first course in calculus) to problems in volumes, centers of gravity, moments of inertia, fluid pressures, gravitational attractions, etc.... I have thought it necessary to state with some fullness some of the leading features of a course in calculus, for there are still colleges in this country in which calculus means a systematic study of Williamson's textbook-formal differentiations, formal integrations, and a total lack of the ideas that are central in the calculus of today.

The tone of these remarks might easily be mistaken today as "pro-reform"- there seem to be all of the requisite nods to the "notion" of limit, the central role of applications, and the inadequacy of traditional, formal textbooks. Yet Prof. Osgood is actually arguing against teaching the mere "notion" of limit. The "central ideas," he says, will be missed. This may not ring true to modern-day reformers, who are willing to base a great deal of the calculus curriculum on the belief that central ideas like continuity, differentiation, integration, etc. can be taught effectively with an intuitive "notion" of limit.

What becomes apparent as Prof. Osgood proceeds, however, is that the "central ideas" he has in mind are something entirely different. He would like calculus students to have a thorough preliminary grounding in the theory of arithmetic and real numbers-something that most modern-day reformers would prefer to leave to subsequent courses in analysis.

Dexterity in the manipulation of formulas is indeed important for later work; but the foundation of algebra is arithmetic, and the arithmetic source of algebraic principles ought not to be lost sight of to any such extent as is at present the case. How far improvement here in school instruction is possible I will not undertake to say, but of this I am sure, that this difficulty must be met and can be met from the start in instruction in calculus. The foundation of the calculus as we have the science to-day is arithmetic.

He seems willing to admit, however, that there is only so much room in the syllabus:

Now it is neither feasible nor desirable to begin a college course in calculus by first developing the number concept...

Prof. F. Morley, one of the editors of the Bulletin, spoke on "The theory of equations; spherical trigonometry; geometric conics" and "On a mechanism for drawing trochoidal and allied curves." He seems to agree with Prof. Osgood's call for developing firm foundations, but, in a line that would please most current reformers, only after the student has developed a more intuitive sense of the subject in an elementary calculus course. His thoughts on developing that intuition through "interaction" sound decidedly modern:

In general the notions of arithmetic and geometry with which a student enters college should be developed by interaction, say through plane and solid analytics and a course in calculus, before either the theory of arithmetic or that of geometry is considered philosophically. This is in effect a plea for the existing order of subjects, if they are presented in a way which leads up to the subjects as they stand, and satisfies both the refined views of the teacher and the common sense of the student. Thus, in the case of calculus, the books used to begin with some 
tremendous generalities. We have either to justify these, or to throw them aside, or to do both. We should do both-first have a calculus proper, of the kind dear to physicists, accurate but not abstract, carefully weeded of difficult generalities; and at a later stage a philosophical theory. To begin with the latter would be to my mind a mistake; the appeal would be to too limited a class.

Professor E.H. Moore, the vice-president of the Society, was also concerned with "fundamental ideas" in calculus, delivering an address titled "Certain fundamental ideas which should be emphasized throughout the undergraduate course." He advocated an intuitive development of the fundamental ideas that would culminate in a more rigorous presentation:

Intuition is by no means to be excluded from mathematical work. On the contrary, in every way let intuition be kept alive and active, but when a new idea is introduced as an intuition let it be sharply defined with the understanding that in so far as subsequent work depends on that intuition a new branch of mathematics is being originated.

It is interesting to consider, then as now, how the pronouncements of "reformers" actually translate into classroom practice. In his day, Moore was a much sought-after speaker on the issues of reform. For many of Moore's students, however, the implementation often fell short of the lofty goals. Moore's classroom is given a vivid evocation in [18]. The setting is a graduate course, and although one might imagine Moore treading more lightly on his undergraduates, the atmosphere is apparent enough:

\begin{abstract}
... Moore had perhaps the most unconventional teaching style, one which tended to appeal to only the most determined and talented students. Like Sylvester before him, Moore often came to his graduate classroom fresh with his latest ideas on the topic under discussion. While this did not generally make for tightly organized and polished lectures, it did instill in his students a "sense of the hunt." With Moore at the blackboard, he and his class would work together to resolve some stubborn detail or to prove some theorem. Sometimes they succeeded, and the class came to a satisfying conclusion; sometimes they failed and dispersed scratching their heads in confusion. Yet regardless of their success or failure, Moore demanded the quick attention of his students, and if they fell behind as his thoughts raced, they soon felt the sting of what Mary Winston termed his "peppery temper." Intending nothing personal by these outbursts, Moore simply forgot about accepted social conventions when overwhelmed by the heat of mathematical thought. Students in his classes may have needed thicker skins than those in his colleagues' courses, but, as one student put it, "it was a proud moment when one who was ambitious and interested found himself in the relatively small group of those who could stand the pace."
\end{abstract}

The "fundamental ideas which should be emphasized throughout the undergraduate course" that Moore had lectured about did not, apparently, include "social conventions." Accordingly, one wonders if the "proud moment" described above, and described by Moore himself in his addresses, might have felt more like a stay of execution to many of his students. We know that the aforementioned Mary Winston, who would survive Moore's class and then leave the department, wrote home to her mother about the psychological trials of Moore's "reforms." [18] (Ms. Winston would go on to become the first American woman to earn a doctorate in mathematics at a German university, in Göttingen, under the direction of the much more encouraging Felix Klein.)

THE NEW EDUCATION. In the late 1800s, teachers who were interested in improving the quality and relevance of instruction in their classrooms - and there were 
many of them-organized themselves into a "movement" that came to be called The New Education. The historian Florian Cajori, writing in 1890, traces the movement's evolution [3]:

\begin{abstract}
About the beginning of the second quarter of this century considerable dissatisfaction came to exist among the public about the college system as it was then conducted in this country. The people demanded a change from the old scholastic methods. Then for the first time arose the now familiar cry against forcing the ancient languages upon all students entering college. It was demanded that greater prominence be given to modern languages, to English literature, to practical mechanics, and that the student should have some freedom in the selection of his studies. Though some few modifications were made here and there in the college courses, the "New Education" did not secure a firm hold upon our colleges until the third quarter of the present century.
\end{abstract}

Mathematicians and mathematics educators interested in the New Education found a forum for their ideas in the newly emerging mathematical publications such as The American Mathematical Monthly. In the very first issue, in January of 1894, the Monthly featured an article entitled "Application of the New Education to the Differential and Integral Calculus," by Prof. Fletcher Durell of Dickinson College [4]. The issues it discussed were considered important enough for the article to be continued into the second issue. Prof. Durell begins:

At a recent meeting of the Physical Society of Great Britain, a paper was read by Mr. F. W. Sanderson, in which was presented a method of teaching mathematics in preparation for science teaching. In the paper and in the discussion which followed, the methods of the so-called new education were emphatically endorsed. The student in each new advance is to begin with the concrete object, something which he can see and handle and perhaps make, and go on to abstractions only for the sake of realized advantages. Drawing is to precede formal Geometry (Euclid) and plotting of curves is to precede Analytical Geometry.

This was a basic principle of the movement: students should have direct experience, even tactile experience, with concrete representations of the objects of study. After presenting his ideas on how to apply this basic principle to the teaching of differentiation and integration, using the so-called "heuristic method," Prof. Durell provides a more expansive summary of The New Education:

This method of presenting the first principles of the Differential and Integral Calculus is in accord with, indeed is developed from the principles of the new education. The method proceeds from the known to the unknown by continuous steps. The idea of slope is already firmly established in the mind of the student from the study of Analytical Geometry. This idea is developed into those of the differential coefficient and the infinitesimal without any sudden leap to functions and abstract continuous quantity.

The method proceeds from the concrete to the abstract. It gives the student at the outset something which he can see, make, and count and hence, develops his self activity. He proceeds to other ideas not mechanically or under dictation but for the sake of clear realized advantages.

In an appeal to the skeptical working mathematician, Prof. Durell quotes from an article in the Educational Review written by Prof. Simon Newcomb [16]. Prof. Newcomb had written:

A practice has come into vogue among professional mathematicians which illustrates the difficulty I have mentioned, and the way in which it may be avoided. The relations among imaginary quantities in algebra are so much more complex than those among real quantities that 
they evade the direct comprehension of even the most expert mathematician. The result was that no progress was made in the study of a subject now at the basis of a large part of mathematics, until Gauss and Cauchy conceived the happy idea of representing the two elements which enter into an imaginary algebraic quantity by the position of a point on a plane. The motion of the point embodied the idea of the variation of the quantity, and the study of the subject was thus reduced to the study of the motion of points; an abstraction was replaced by a concrete representation. The result was that, in the conception of writers on the subject, position speedily took the place of quantity; the word "point" replaced the word "value," and in this way an extended branch of mathematics was constructed, which would not have been possible had the abstract variable of algebra not been replaced by the moving point of geometry. If the greatest mathematical minds feel such an aid to be necessary to their work, why should not a corresponding aid be offered to the farmer's boy, who is engaged, year after year, in struggling with numbers, of whose relations to sensible objects he can have no clear conception?

And, Prof. Durell adds:

... offered to the student who with no extended preliminary mathematical training takes up the study of the Differential and Integral Calculus, the most difficult perhaps in the range of the curriculum? Furthermore, as the first conceptions of the theory of functions are now usually given in the geometric form, one of the advantages of the method of teaching the Calculus here presented is that it thus also opens the way to the general treatment of the subject where the complex variable is included.

In the classroom, the concrete representation of abstract ideas promoted by The New Education often took the form of mathematical models. "Mathematical models," at the time, did not mean anything like the synthetic cycles of application and reevaluation so central to today's reforms - it meant actual, physical objects made of wood, string, and plaster. Geometric models were carefully crafted to demonstrate the interplay between the analytic and the geometric, the intricacies of which were very much on the nineteenth century's cutting-edge. Today, this same interplay is more likely to be illustrated through carefully crafted programs on computers and graphing calculators. (Physical "models," in the modern sense of "models of knowledge construction," continue their presence in the form of mathematical "manipulatives.")

Even in the 1890s, however, there was nothing essentially "new" about providing students with multiple representations of abstract ideas. Mathematical models had been a part of mathematics instruction since at least the 17th century. For example, in a volume titled Stereometry Or, the Art of Gauging... [5], written in 1689 by Thomas Everard, self-proclaimed "Philomath," there are any number of concocted "applications" that require some kind of three-dimensional visual acuity. One of them requires finding the volume of an ale tun in the shape of a pyramidal frustum with bases that range from a "trigon" to a dodecagon. To help with the visualization, there is an appendix of drawings showing the volumes involved. If these drawings alone are not enough to awaken the reader's spatial imagination, then an advertisement inside the title page informs the reader that geometric models are available at a particular shop in London (and "only" at this shop), the address of which is duly noted. There was money to be made in "new" mathematics, even then.

In America, the use of mathematical models goes back to at least the beginning of the nineteenth century, when the first common schools attempted to emulate the "objective" practices of their Swiss and German counterparts. Sets of geometric solids were sold to the new schools with claims that they would help teachers present a common curriculum. The market for these models was maintained well into the early parts of the 20th century with fervent calls for, successively, "Object-Oriented Instruction," "Technical Training," "Art Education," and "Exact Thinking." School boards and 
government commissions formalized the arrangement, making geometric models a required component of mathematics instruction in many states. For example, an inspector's report for the Connecticut State Board of Commissioners for Common Schools from the 1830s includes on its checklist the questions "Does the school have a set of geometric solids?" and "Does the school have a cube that could be divided to illustrate the process of taking a cube root?" [10] Business was so good during the nineteenth century that model makers were able to diversify into much more lucrative catalogues of "Mathematical Apparatus," which included everything from the latest in "noiseless" drawing slates and elegant "pointing rods" to hand-crafted "numerical frames," made of the finest woods. There was eventually a backlash, however, as teachers began to complain that the expensive, and increasingly complicated apparatus was driving the curriculum. The parallels with today's classroom computers probably do not have to be pointed out.

American universities of the nineteenth century were, for the most part, teaching institutions that carried forward the lessons of the common schools, preparing (mostly) young men for their careers. In the middle of the century, America began to establish its first technical colleges, looking to the French military academies and the École Polytechnic for guidance. The French schools had been heavily influenced by the example of Gaspard Monge, who had introduced mathematical models into technical training with his "descriptive geometry" for representing three-dimensional objects in two-dimensions. The models of Monge and his students were, accordingly, elaborately stringed representations of various projective paths and their motions. Collections of these models were bought up by many of the new American technical colleges.

The idea of a "research university" did not emerge in the United States until the end of the nineteenth century. Looking to Europe again, mathematics departments found inspiration in the German system, which was then promoting the construction and use of mathematical models in graduate education. Felix Klein had established a laboratory for the construction of mathematical models in Munich, employing the labors of many of his graduate students, and when he brought a large collection of these models to the German Universities Exhibit at the World's Colombian Exhibition in Chicago in 1893, sales to American universities were brisk. This was exactly the time when The New Education began to be debated in the American mathematical journals. Far from new, the idea of multiple representations of mathematical concepts already had a long history in both elementary and college education. Today, it has simply been repackaged, with calls for increased use of computer visualizations, and names like "The Rule of Four."

HARVARD CALCULUS. The struggles to develop a "Harvard calculus" more than a century ago also have many modern resonances. In a biography of Benjamin Pierce, the chair of the Harvard mathematics department from 1831 until the time of his death in 1880, Prof. F. P. Matz wrote in the MONTHLY [13]:

In the reforms incident to the New Education, Harvard has always taken a prominent part and Benjamin Peirce was an enthusiastic advocate. .

The biography didn't appear until 1895, and Prof. Matz may be guilty of applying contemporary categories, such as New Education, to Peirce's ideas; but if one is willing to accept that The New Education was only a new name for a collection of ideas with a much longer history, then Pierce and the Harvard mathematics department were undoubtedly on the forefront of the movement. Prof. Matz notes that "Such advanced 
courses of mathematics as he offered to students, in 1848, had never before been offered to American students by any other professor in any other American college."

One of Prof. Peirce's innovations was to take the unprecedented step of writing his own textbooks, including the two-volume set Elementary Treatise on Curves, Functions, and Forces. Prof. Matz writes:

The preparation of mathematical text-books was begun by Professor Peirce, immediately on beginning his career as teacher of Mathematics in Harvard College. ... All of his works are models of conciseness, perspicuity, and elegance; and they all evince extraordinary originality and genius.

\section{Elaborating on Peirce's style of writing, Prof. Matz notes:}

Professor Peirce was a transcendentalist in mathematics ... The thing he distrusted was routine and fanatical method, whether new or old; for thought, salient, vital, co-operative thought, in novel or in ancient aspects, he had nothing but respect and furtherance.

The historian Florian Cajori also makes note of the Harvard mathematics department's influence on The New Education. He identifies John Farrar, Peirce's predecessor as chair, as "among the first to introduce important reforms in the mathematical teaching in American colleges." Farrar's chief contribution to "reform," it seems, was in translating European texts in mathematics, and then teaching from these translated sources in his courses, rather than from the many "interpretations" that were then available in English.

Farrar's classes certainly sound different. Here is a reminiscence by one of his students [3]:

The professor had no notes, and commenced his lecture in a conversational tone and manner, very much as if he were explaining his subject to a single learner. But whatever the subject, he very soon rose from the prosaic details to general laws and principles, which he seemed ever to approach with blended enthusiasm and reverence, as if he were investigating and expounding divine mysteries. His face glowed with the inspiration of his theme. His voice, which was unmanageable as he grew warm, broke into a shrill falsetto; and with the first high treble notes the class began to listen with breathless stillness, so that a pin-fall could, I doubt not, have been heard through the room. This high key once reached there was no return to the lower registers, nor any intermission in the outflow and quickening rush of lofty thought and profound feeling, till the bell announced the close of the hour, and he piled up all the meaning that he could stow into a parting sentence, which was at once the climax of the lecture, and the climax of an ascending scale of vocal utterance higher, I think, than is within the range of an ordinary soprano singer.

Regarding Benjamin Peirce, Cajori says that his textbooks "were adopted as soon as they came from the press." Apparently, they formed the basis of an "elective system," which tracked students according to their interests and abilities. Cajori writes:

In the catalogue for 1838 we notice important changes. The Freshmen studied Peirce's Geometry and Algebra; the Sophomore class was divided into three sections, of which the first pursued practical mathematics, including mensuration, dialing, construction of charts, surveying, the use of globes and instruments in surveying, during the first term; and during the second term the general principles of civil engineering, nautical astronomy, and the use of the quadrant. This section was evidently intended to meet the demands of the time for practical knowledge, without having first laid a broad and secure foundation. But little could be accomplished in civil engineering without a knowledge of calculus. The second section reviewed arithmetic, geometry, and algebra; then took up conic sections, fluxions, and the mathematical 
theory of mechanics. The third section, intended for students of mathematical talents and taste, pursued analytic geometry, theory of numbers and functions, differential and integral calculus, and mechanics.

Peirce's textbooks, however, were not popular. Cajori states: "The facts are that Prof. Peirce's textbooks were found very difficult." The freshmen, who were required to study out of Peirce's texts, were particularly unhappy:

Mathematical studies were not popular with them; they complained of over-work. In 1839, the committee on studies reported that "the mathematical studies of the Freshman class are so extensive as to encroach materially upon the time and attention due to other branches." ... Repeated and loud complaints were made at Harvard that the mathematical teaching was poor. The majority of students disliked the study and dropped it as soon as possible.

By 1848, only five students "survived" Peirce's Curves and Functions. A committee was impaneled once again, charged with digging to the bottom of the "so very decidedly unpopular" status of mathematics at the University. The majority on the committee reported that "the text-books were abstract and difficult," and that "there are other mathematical works of no small merit, which embraced the same subjects as the text-books now used, which were much less difficult of comprehension." However, a minority on the committee came to a different conclusion:

Your minority of the committee believe that these text-books, by their beauty and compactness of symbols, by their terseness and simplicity of style, by their vigor and originality of thought, and by their happy selection of lines of investigation, offer to the student a beautiful model of mathematical reasoning, and lead him by the most direct route to the higher regions of the calculus. For those students who intend to go farther than everyday applications ...this series of books is, in the judgment of the minority, by far the best series now in use.

The minority opinion gives some sense of the nature of Peirce's "reforms." The "most direct route to the higher regions of the calculus" is quite the opposite of the circling approach through applications and multiple representations advocated by many of today's reformers. Peirce's "compactness," "terseness," etc., prized by a minority of mathematicians on the committee, was exactly the source of the student difficulties.

Outside of Harvard, Peirce's texts had a wide influence. One of Peirce's students, the Rev. Thomas Hill, who later became a president at Harvard, writes [3]:

They were so full of novelties that they never became widely popular, except, perhaps, the Trigonometry; but they had a permanent influence upon mathematical teaching in this country; most of their novelties have now become common-place in all text-books. The introduction of infinitesimals or limits into elementary books; the recognition of direction as a fundamental idea; the use of Hassler's definition of sine as an arithmetical quotient, free from the entangling alliance with the size of the triangle; the similar deliverance of the expression of derivative functions and differential coefficients from the superfluous introduction of infinitesimals; the fearless and avowed introduction of new axioms, when confinement to Euclid's made a demonstration long and tedious-in one or two of these points European writers moved simultaneously with Peirce, but in all he was an independent inventor, and nearly all are now generally adopted.

Here Peirce sounds like a more modern reformer, freeing essential ideas from their inessential accouterments, inventing novel presentations to accomplish his objectives. Not all of Peirce's "novelties," however, were as influential as Rev. Hill suggests. One example was his insistence that the symbols $\pi$ and $e$, generally accepted at the time, 
were "inconvenient." Peirce advocated the symbols $\odot$ and $๑$, respectively, to take their place. [2]

Unfortunately, Peirce was evidently another example of an educational reformer who was not always able to translate his lofty ideas into effective classroom practice. Certainly, many students seem to have been unable or unwilling to keep pace with his demands. In 1925, the MONTHLY published a monograph dedicated to Peirce [1], and it is filled with the recollections of his students. Time and again, they recall his chaotic classroom presence and his angry impatience with detail. His blackboard technique often involved only a small corner of the board, which he would quickly erase at the sign of trouble, with the instruction that his students should make the necessary corrections when they went over their notes. One student recalls:

I can see him now at the blackboard, chalk in one hand and rubber in the other, writing rapidly and erasing recklessly, pausing every few minutes to face the class and comment earnestly, perhaps on the results of an elaborate calculation, perhaps on the greatness of the Creator ... I remember his turning to us in the middle of a lecture on celestial mechanics and saying very impressively, "Gentlemen, as we study the universe we see everywhere the most tremendous manifestations of force. In our own experience we know of but one source of force, namely will. How can we help regarding the forces we see in nature as due to the will of some omnipresent, omnipotent being? Gentlemen, there must be a GOD."

Eventually, Peirce was able to reach a compromise with the administration, convincing them that the elective system should allow "lower-level" students to voluntarily discontinue their study of mathematics after the first year. The president of the university deemed the compromise "acceptable to both students and parents," and Peirce promptly discontinued his teaching of all lower-division courses. (The instruction in many of these courses was taken up by his son.) A student recalls this time:

As to the mathematical instruction, this reform (elective system) was an especial benefit, for Professor Peirce's genius reveled in the new sensation of having voluntary pupils, and he gave a few of us his Curves and Functions as lectures...

Indeed, "genius" is the awe-struck term often applied by the students that were able to stick it out in Peirce's advanced courses. They generally admitted, however, that he "inspired rather than taught," with one student recalling that "I could not understand much that he said; but it was splendid." Another starry-eyed account of Peirce toward the end of his career goes like this:

The appearance of Professor Benjamin Peirce, whose long gray hair, straggling grizzled beard and unusually bright eyes sparkling under a soft felt hat, as he walked briskly but rather ungracefully across the college yard, fitted very well with the opinion current among us that we were looking upon a real live genius, who had a touch of the prophet in his make-up.

We do not have books dedicated to testimonials from the many students who were lost to Peirce's "reforms," but one account, given by a student who tried and failed to meet Peirce's demands, survives [3]:

Long after, when I was indicted for the attempted rescue of a fugitive slave, and the prison walls seemed impending, I met him in the street and told him that if I were imprisoned I would have time to read Laplace's Mécanique Céleste. "In that case..." said the professor, who abhorred the abolitionists, "I sincerely wish you may be." 
THE GOVERNMENT REPORT. In 1890, a decade after the end of Benjamin Peirce's tenure at Harvard, with his texts still widely used and The New Education beginning to receive a great deal of attention, the U.S. Bureau of Education commissioned a report on the state of mathematics instruction across the country. Its author was Florian Cajori, who would go on to become one of America's leading educators and a thoughtful writer on the history of mathematics, its teaching, and its role in liberal education. Part of the justification for the government study was given in the quotation from Cajori at the beginning of this article, which came from the report's introduction. It goes on:

The most melancholy thought in this connection is that, after all, our boys and girls acquire only a deficient knowledge of this subject. Persons who had opportunities for comparison assure us that the American boy does not "figure" as well as the German boy.

Indeed, up until World War I, Germany provided the model for unflattering comparisons of America's "deficient" achievements. (A role to which Japan has been assigned in more recent years.)

To find out what was happening in mathematics classrooms around the country, Cajori drew up a questionnaire that contained what he felt were the most important questions of the contemporary debate. They included:

- Are students entering your institution thorough in the mathematics required for admission?

- Is the percentage of students electing higher mathematics increasing or decreasing?

- Does the interest in mathematics increase as students advance to higher subjects?

- What mathematical subjects are preferred by students?

- Are topics assigned to students for special investigation?

- Is any attention given to the history of mathematics? Does it make the subject more interesting?

- How does analytical mathematics compare in disciplinary value with synthetical?

- What method of teaching the calculus do you favor, that of limits, the infinitesimal, or some other? Does the infinitesimal seem rigorous, and to satisfy the mind of the student?

- Do scientific or classical students show greater aptitude for mathematics? Which sex?

- In what other subjects are good mathematical students most successful? In what least successful?

- Do you favor memorizing rules in algebra? What reforms are needed in teaching the same?

- To what extent are models used in geometry? ... What reforms are needed in teaching the same?

- State the time of your special preparation for teaching mathematics, number of hours you teach per week, and what other subjects you teach.

Cajori tallied the responses from 213 colleges, universities, and normal schools. Among the colleges and universities responding were Brown, Columbia, and Howard (not Harvard); M.I.T., Rose Polytechnic Institute, and the Naval Academy; Ohio State, Kansas State, and the State University of Iowa; The University of North Carolina, The University of Dakota, and DeLand University of DeLand, Florida; Mt. Holyoke, Mt. St. Mary's, and The Kansas City Ladies College; Bowdoin, Williams, and Miami of 
Ohio; The German-English College, The National Deaf-Mute College, and The Seminary West of the Suwannee River. There was also a response from Pierce Christian College in College City, California, mailed in by a certain "D. Hughes." Overall, the report provides a broad portrait of the general practice of mathematics teaching in this country one hundred years ago.

The responses, like the questions, have a very familiar ring to them. For example, regarding whether or not interest in mathematics increases as students advance, we hear:

- "... so long as the student sees the bearing of his work upon practical scientific investigation or can be assured that it has such a bearing"

- "All who understand the principles show a growing interest"

- "With the best students only"

and, in an out-lying opinion from Furman University,

- "...the more evolved or abstruse the matter, the greater the interest to those who succeed"

Concerning the students' preferred mathematical subjects, most teachers will recognize the timelessness of the response:

- "Their preferences are generally for the particular subject which they have had the best elementary training in"

Some of the questions forced the respondents to take a side. Regarding the use of student research projects implied in the question about assigning "special investigations," the responses came out about evenly. On the positive side, we hear:

- "They... form a very essential part of the work"

- "Independent problems given in all the classes for solution, reported on paper"

On the negative side:

- "Not to undergraduates"

- "The man who pursues original investigation with the average student will make a failure"

The report finds that very little attention was given to the history of mathematics at the majority of schools, even though it notes that "No one answered that it did not make the subject more interesting - a clear case."

Most schools reported that "scientific" male students had a greater aptitude for mathematics than "classical" female students, though the responses from the women's colleges disagree, generally indicating that their "classical" students show the greatest aptitude. The respondent from The Cooper Normal College in Daleville, Mississippi says:

- "Males in quantity, females in quality."

There were, in general, many more schools that did not recommend the memorization of algebraic rules than those that did, and the reasons sound familiar: 
- "... not to... young boys, who contract the incurable habit of learning it by rote"

- "Rules and principles are to be deduced from examples"

- "Algebra should be seen"

- "... less toughing, disgusting gymnastics"

- "The teacher should assist the pupil to make his own rules"

- "Drill on... raison d'être"

- "More of an inductive method; and the abolition of much that may be interesting theoretically, but of little practical use"

- "Students should be taught to think! think!! think!!!"

- "The pupils learn to do by doing"

- "Less formality and more 'realism",

and, in an interesting metaphor from the University of Missouri School of Mines,

- "Rattle the bones of the algebraic skeleton... and show it in its living, breathing continuity"

There were also many observations about the kind of teaching that best complemented the non-mechanical approach:

- "Teaching needs to be less mechanical"

- "Less memorizing and more thinking, both on the part of the teacher and student"

- "... less blackboard work"

- “... putting into words the ideas conveyed by its symbols, equations, and operations"

- "Let us have live, enthusiastic, and competent teachers-such as will teach the subject rather than the text-book"

One respondent noted:

- "In the larger colleges algebra is mostly taught by tutors, who hold temporary appointments, and do not expect to make teaching their life work. Algebra as well as calculus should be taught by a permanent professor."

Responses that did advocate the essential benefits of memorization and drill noted that:

- "The chief cause of failure in many cases is not doing enough miscellaneous examples for practice"

- "I recommend the memorization of rules, unless the pupils furnish a good, working rule of their own (a rare case)"

- "It is only practice that makes perfect"

- "...the German system"

- "I prefer formulas"

- "We need no reforms"

Only one respondent, a Prof. H.C. Davis from the Agricultural and Mechanical College of Starkville, Mississippi, refused to take sides; he noted calmly that

- "The method of teaching must, I think, vary under different circumstances" 
Thoughts on calculus instruction were more evenly divided, with a slight majority of respondents preferring the method of limits to the method of infinitesimals. This was usually because of misgivings about foundational issues. As one respondent said,

- "The philosophy at the base of the (infinitesimal) method seems to involve one in a maze of absurdities"

When student preferences were reported, however, the infinitesimal method was generally preferred-it was sufficient to "satisfy the mind" of most students, who found it simpler and more intuitive. As the respondent from the Rose Polytechnic Institute related:

- "... it is my experience that the (infinitesimal method) more quickly removes the logical difficulties in the way of the beginner"

This dichotomy between what teachers and students found "best" and "logical" was brought out by the question "How does analytical mathematics compare in disciplinary value with synthetical?" The fact that the question is phrased in terms of "disciplinary" value already shows a teacher's point of view, and the emphasis begs for the predictable flood of responses favoring the analytic. When the responses are read carefully, however, the decision about which method to emphasize while teaching seems less clearcut:

- "I think both are necessary for a full mental development"

- "With the majority of my students, more satisfactory results are obtained through the synthetical"

- "... as well ask whether braces or tie-rods are of most service in a bridge-truss"

- "The synthetical is better for younger students; the analytical for the more mature"

- "Analyzing the whole into its elements is valuable, but building the whole from elements is very valuable"

- "That depends on the peculiar natural bent of the pupil's mind"

Still, some respondents make it quite clear that they not only prefer analytic methods, but find synthetic methods a dangerous corruption of mathematical practice:

- "In my judgment the analytical is so far superior to the synthetical that there is left little room for comparison. Permit me to say that reason wants light, not darkness."

- "I can not say fairly, for my teaching has been wholly in analytical mathematics"

It is also of interest to look at the response to the educational "technology" of the time-mathematical models. The use of mathematical models in the classroom caused the same kind of divisive debates that surround modern visualization technology. Then, as now, usage varied from place to place and from instructor to instructor. The most enthusiastic endorsements in the report come from teachers who used the models to help students visualize problems in three-dimensional calculus and the "higher surfaces" of descriptive geometry. Some instructors had their students construct models as a regular part of their courses, and one respondent, from the State Agricultural College in Fort Collins, Colorado, was such a free-thinker that he used models "out-doors." Some schools boasted about the specifications of their expensive, up-to-the-minute collections: 
- "Full set of Schröder's (Darmstadt) models"

- "We have twenty-six fine models of warped and single-curved surfaces"

- "We have about one hundred dollars worth of models for pure mathematics"

Other collections, such as the one at Dickinson college, seemed pitiful by comparison:

- "None except sphere and cone"

Outright hostility toward the use of models was rare, though not unheard of:

- “... find them hurtful rather than helpful. 'Normal School' methods are a failure."

Typical among the responses from those that were not making use of models were questions of their value beyond the level of "beginners." A few respondents, however, simply stated that they were personally more comfortable "drawing figures on the board." One respondent said that models weren't used because

- "I prefer that students should learn as soon as possible to form mental pictures"

The method by which students would learn this skill was unspecified. Sometimes the reasons for not using models in the classroom were more prosaic, though equally recognizable:

- "They are used to a very limited extent, because the college is not supplied with them"

- "Only slightly, because we are not able to afford them"

- "Hitherto but little; henceforth very great (if the appropriation asked of the State be granted)"

The report also gives us an opportunity to check on the extent to which the academic community has progressed with labor-related issues. Reporting on the number of hours per week that teachers spent in the classroom and in preparation, the majority of responses fell somewhere in the range of 10-30 hours/week, though it was noted that "... this does not include office hours." At the extremes were the respondent from Niagra University, who taught only two hours per week and prepared in a mere half hour, and the incredibly energetic "D. Hughes," who logged in at forty-one hours per week. The teaching load was considerably lower at institutions where "assistants" were available to take on some of the load, and at Adrian College in Adrian, Michigan, the respondent reports that

- "My assistant teaches all up to and including analytic geometry, moral science, \&c."

As noted earlier, these assistants were usually part-time employees who had little chance of turning their teaching into a permanent career. One presumes that the teaching of "moral science" was handed over from one part-time employee to the next.

It is difficult to summarize the incredible number of fascinating particulars that make up the report, and Cajori doesn't really try. What he does offer, however, are individualized portraits of some of the respondents. For example, he describes the innovative teaching style of Prof. T. H. Safford at Williams College, who used, and advocated, the "heuristic method." Cajori describes the method as follows: "The heuristic method is, in general, the method in which the pupil's mind does the work." He then 
adds, perhaps unnecessarily, "It is a slow method." Among other things, Prof. Safford used the "rule of three":

Safford strongly recommends the parallelism of the two main mathematical subjectsarithmetic including algebra, and geometry including trigonometry and conic sections. Thereby the study of algebra and geometry can be extended over a longer period of time. According to his ideal programme of study, primary arithmetic is accompanied by notions of form and drawing; arithmetic through rule of three, by rudiments of geometry; universal arithmetic and simple equations, by one or two books in plane geometry; algebra through quadratics, by plane geometry; advanced algebra, by solid geometry, conic sections, plane trigonometry, \&c.

Although the "rule of three" mentioned here, as a subject in arithmetic, is not the same Rule of Three (or Four or Five) advocated by many of today's reformers, the integrated approach of Prof. Safford's "ideal programme of study" surely captures some of the same spirit. Prof. Safford himself assures that the flexibility of the program is part of its enduring legacy:

Of course this programme is somewhat variable, but the main principle, that a course of arithmetic must run parallel with one of geometry from the beginning of a school course to the end, is one which is laid down by the best educators since Pestalozzi's time.

Although Cajori is not able to summarize adequately the many nuances of his findings, he is able to capture the anxious uncertainty of so many unsettled "discussions":

The mathematical teaching of the last ten years indicates a "rupture" with antiquated traditional methods, and an "alignment with the march of modern thought." As yet the alignment is by no means rectified. Indeed it has but barely begun. The "rupture" is evident from the publication of such works as Newcomb's series of mathematical text-books, and recent publications on the calculus..."

At which point Cajori goes on to list a "rupture" of newly published textbooks, on subjects ranging from algebra to differential equations, each one promoting its own prescription for reform.

THE "NEW" REFORMS. As we turn into another millennium, one hundred years after the "reforms" of the New Education, the American mathematical community is filled again with commencement de siécle angst about its collective educational endeavors. Well-intentioned efforts to pass mathematics on to the next generation have "reformers" moving in many different directions. Collisions are inevitable, and our conferences and journals are filled with the noise. We hear that mathematics education is in "turmoil," facing a "crisis." We hear about the "math wars." With all parties convinced that nothing less than the good of mathematics is at stake, the noise grows ever louder.

If we could hear history's lessons, we might be more willing to see the current "crisis" as just another episode in a long historical "discussion" about the nature of mathematics itself. The issues haven't been settled in a century-many centuries, in fact - and they will not be settled in this one. The debate endures because there is something inherent in mathematical practice that always leads to these disagreements. Mathematics, and the experience of mathematics, is chaotically, wonderfully, multitudinous. Nevertheless, the many motions within mathematics education have always managed to find a collective average motion that carries the subject fruitfully forward. Mathematics survives. 
In 1912, Bertrand Russell, as even-headed a member of our profession as we are likely to find, wrote about the "problems" of philosophy [21, p.61]. He wondered about the value of a lifetime of struggle that could never reach a final, satisfying conclusion. Though he may have been talking about "philosophy" in general, we could just as well substitute "pedagogy," or whatever else it is that is keeping us up at night:

Philosophy is to be studied, not for the sake of any definite answers to its questions, since no definite answers can, as a rule, be known to be true, but rather for the sake of the questions themselves; because these questions enlarge our conception of what is possible, enrich our intellectual imagination and diminish the dogmatic assurance which closes the mind against speculation..."

\section{REFERENCES}

1. R. C. Archibald, editor, Benjamin Peirce, The Mathematical Association of America, Oberlin, 1925.

2. F. Cajori, A History of Mathematical Notations, Open Court Publishing Company, La Salle, 1928.

3. F. Cajori, The Teaching and History of Mathematics in the United States, Government Printing Office, Washington 1890.

4. F. Durell, Application of the New Education to the Differential and Integral Calculus, Amer. Math. Monthly 1 (1894) 15-19, 37-41.

5. T. Everard, Stereometry, Or, The Art of Gauging Made easie by the Help of a New Sliding-Rule Which Shews The Area's of Circles in Gallons and Barrelrs and the Square and Cube-Root of any Number under 100000 by inspection; and also Resolves many other Arithmetical Problems without Pen or Compasses: With An Appendix Of Conick Sections, In Which The Nature and Original of Several Solids (frequently mentioned in Books of Gauging) is Explained, and their Magnitudes compared, Peacock, London, 1689.

6. J. Ewing, editor, A Century of Mathematics Through the Eyes of the Monthly, The Mathematical Association of America, Washington, D.C., 1994.

7. W. Hawney, Hawney's Complete Measurer, Or, The whole Art of Measuring: Being A Plain And Comprehensive Treatise On Practical Geometry And Mensuration: Preceded By Decimal And Duodecimal Arithmetic, And The Extraction Of The Square And Cube Root: Adapted To The Use Of Schools And Persons Concerned In Measuring, Gauging, Surveying, \&c., Cochran and McLaughlin, Philadelphia, 1801.

8. J. Holbrook, Apparatus Designed for Families, Schools, Lyceums and Academies, Allen and Ticknor, Boston, 1833.

9. P. S. Jones, editor, A History of Mathematics Education in the United States and Canada, National Council of Teachers of Mathematics, Washington, D.C., 1970.

10. P. Kidwell, American Mathematics Viewed Objectively: The Case of Geometric Models, in Vita Mathematica, The Mathematical Association of America, Washington, D.C., 1996.

11. S. G. Kohlstedt, Parlors, Primers, and Public Schooling: Education for Science in Nineteenth Century America, Isis 81 (1990) 425-445.

12. W. H. Maltbie, The Undergraduate Mathematical Curriculum, Bull. Amer. Math. Soc. 7 (1901) 14-24.

13. F. P. Matz, Benjamin Peirce, Amer. Math. Monthly 2 (1895) 172-179.

14. W. Mueller, Lost Geometry, introductory essay for the Catalogue of Mathematical Models at the University of Arizona, Tucson: Department of Mathematics, University of Arizona (1998).

15. W. Mueller, Mathematical Wunderkammern, preprint

16. S. Newcomb, Educational Review 4 (1892) 279.

17. New England Association of Colleges and Preparatory Schools; Addresses and Proceedings at the Annual Meeting, 1888.

18. Karen Hunger Parshall and David E. Rowe, The Emergence of the American Mathematical Research Community, 1876-1900: J. J. Sylvester, Felix Klein, and E. H. Moore, The American Mathematical Society, Providence, 1994.

19. Karen V. H. Parshall and David E. Rowe, Embedded in the Culture: Mathematics at the World's Colombian Exposition of 1893, Math. Intelligencer 15 (1993) 40-45.

20. A. Peabody, Harvard Reminiscences, Boston, 1888.

21. B. Russell, The Problems of Philosophy, Home University Library, Oxford, 1912.

22. Deborah Jean Warner, Commodities for the Classroom: Apparatus for Science and Education in Antebellum America, Annals of Science 45 (1988) 387-397.

23. B. S. Whitman, Mary Francis Winston Newson, Math. Teacher 76 (1983) 576-577. 
WILLIAM MUELLER is Mathematics and Education Specialist at MathSoft, Inc. He earned his undergraduate degree in mathematics at MIT, and his Ph.D. in mathematics at Duke University. He has been a participant in many national educational reform projects, including Duke's Connected Curriculum Project, the Five Colleges' Calculus in Context project, and the Harvard calculus and precalculus projects. He writes and designs online learning materials for MathSoft's Learning Site (learning.mathsoft.com).

MathSoft, Inc., 101 Main St., Cambridge, MA 02142

wmueller@alum.mit.edu

\section{A Sherwood Forest Puzzle}

There, in Sherwood Forest, lived 10,201 people. Everyone had a mate except the priest. Each person had written a song. Singing was contagious.

Every song was sung to every person by a singer. (This includes the fact that each person's own song was sung to that person by some singer.) The priest, to whom everyone sang one's song, had a song that everyone sang to oneself. The priest sang to each person the song written by that person's mate and, having no mate, he sang his own song to himself.

Any singer who sang to a first person the song of the singer of a second person's song to a third, was the same singer who sang to the singer of the third person's song to the first person the song of the second person.

If it was Marian who sang Robin's song to Little John, who sang Little John's song to Robin? Who sang Marian's song to her?

See the March issue for a solution.

Contributed by Iraj Kalantari, Western Illinois University 